\title{
Difference squeezing of the optical fields in degenerate six-wave interaction process
}

\author{
B. K. Choudhary ${ }^{1}$ and D. K. Giri ${ }^{2 *}$ \\ ${ }^{1}$ Department of Applied Physics, Cambridge Institute of Technology(R), Tatisilwai, Ranchi \\ ${ }^{2}$ Department of Physics, P. K. Roy Memorial College, Dhanbad
}

Available online at: www.isroset.org

Received: 16/Mar/2018, Revised: 06/Apr/2018, Accepted: 20/Apr/2018, Online: 30/Apr/ 2018

\begin{abstract}
We studied squeezing in the difference of the field amplitude in degenerate six wave interaction process, which is a higher-order squeezing effect. It is shown that for uncorrelated modes the normal squeezing in the difference-frequency field directly depends on the difference squeezing of input field modes. It is established that the amplitude-squared squeezing of the fundamental feeds directly into the normal squeezing of the signal mode. Detection of difference and amplitude-squared squeezing in this process is also studied. It is found that squeezing is greater in stimulated process than in spontaneous interaction.
\end{abstract}

PACS Nos.: 42.50.Dv, 42.50.Lc, 42.65.Dr, 42.65.Ky.

Keywords: Squeezed States, Multiwave Mixing, Difference Squeezing, Photon Number, Amplitude-Squared Squeezing.

\section{INTRODUCTION}

Squeezed states of light $[1,2]$ has drawn the greater attention of the community owing to its low-noise property $[3,4]$ with an application in high quality telecommunication [5], quantum cryptography [6,7], and so forth and also rapid development of techniques for making higher-order correlation measurements in quantum optics [8,9]. It has been many theoretical and experimental developments takes place in a various optical processes, such as parametric amplification [10, 11], harmonic generation [12-13], multi-wave mixing processes [14-18], Raman [19], hyper-Raman [20] etc. Hong and Mandel [21, 22], Hillery [23, 24], and Zhan [25] for improving the performance of many optical devices and optical communication networks. Higher-order sub-poissonian photon statistics of light have also been studied by Kim and Yoon [26]. Recently, Prakash and Mishra [27, 28] have reported the higher-order sub-poissonian photon statistics and their use in detection higher-order squeezing. Garcia Fernandez et al [29] have worked on higher-order squeezing in single mode multi-photon absorption process. Further, another type of higher-order squeezing, called sum and difference squeezing were proposed by Hillery [30] for the two modes. These concepts have recently been generalized to include three modes for sum and difference squeezing [31] as well as an arbitrary number of modes for sum and difference squeezing [32-34]. In a recent publication [35, 36] we have reported that squeezing is found to be maximum in amplitude-cubed followed by amplitude squared and amplitudesqueezing and squeezing in the signal mode depends on the amplitude-squared squeezing of the fundamental mode for higherorder coupling respectively in six-wave mixing process.

The aim of this paper is to study another type of higher-order squeezing i.e. difference squeezing of the optical fields in degenerate six-wave interaction process, which has not been studied earlier. The paper is organized as follows: Section 2 gives the definition of higher-order squeezing. We establish the analytic expression theoretically and discuss the results on difference squeezing of the optical fields in signal mode in degenerate six-wave interaction process in section 3. Section 4 incorporates results and discussion. Finally, we conclude the paper in section 4.

\section{DEFINITION OF HIGHER-ORDER SQUEEZING}

Higher-order squeezing is the higher powers of the field amplitude [23], which are characterized by reduced quantum fluctuations in one quadrature at the expense of the increased fluctuations in the other quadrature of the field. It is a special class of minimum uncertainty state. 


\subsection{Amplitude-squared squeezing of single mode}

The amplitude-squared squeezing may be defined by its real and imaginary parts as

$$
\mathrm{Y}_{1}=(1 / 2)\left(\mathrm{A}^{2}+\mathrm{A}^{\dagger 2}\right)
$$

and

$$
\mathrm{Y}_{2}=(1 / 2 i)\left(\mathrm{A}^{2}-\mathrm{A}^{\dagger 2}\right)
$$

where $\mathrm{A}$ and $\mathrm{A}^{\dagger}$ are the slowly varying operators with time t. For a single mode, they are given by

$$
\mathrm{A}=\mathrm{a} \exp (\mathrm{i} \omega \mathrm{t}) \text { and } \mathrm{A}^{\dagger}=\mathrm{a}^{\dagger} \exp (-\mathrm{i} \omega \mathrm{t})
$$

where $\mathrm{a}^{\dagger}(\mathrm{a})$ are creation (annihilation) operators of the electromagnetic field with frequency $\omega$. These operators satisfy the commutation relation

$$
\left[\mathrm{Y}_{1}, \mathrm{Y}_{2}\right]=\mathrm{i}\left(2 \mathrm{~N}_{\mathrm{A}}+1\right)
$$

where $\mathrm{A}^{\dagger} \mathrm{A}=\mathrm{N}_{\mathrm{A}}$ is the photon number operator in pump mode.

The equation (4) leads to the uncertainty relation $(\hbar=1)$

$$
\Delta \mathrm{Y}_{1} \Delta \mathrm{Y}_{2} \geq\left\langle\left(\mathrm{N}_{\mathrm{A}}+1 / 2\right)\right\rangle
$$

where $\Delta \mathrm{Y}_{1}$ and $\Delta \mathrm{Y}_{2}$ are the uncertainties in the quadrature operators $\mathrm{Y}_{1}$ and $\mathrm{Y}_{2}$ respectively.

Amplitude-squared squeezing exist if

$$
\left(\Delta \mathrm{Y}_{\mathrm{i}}\right)^{2}<\left\langle\left(\mathrm{N}_{\mathrm{A}}+1 / 2\right)\right\rangle \quad \text { where } \mathrm{i}=1 \text { or } 2
$$

These states have purely quantum mechanical nature i.e. a state which satisfies equation (6) exhibits non-classical features.

Expressing the variance $\left(\Delta \mathrm{Y}_{\mathrm{i}}\right)^{2}$ classically in the P-representation of the state one can show

$$
\left(\Delta \mathrm{Y}_{\mathrm{i}}\right)^{2}=\left\langle\left(\mathrm{N}_{\mathrm{A}}+1 / 2\right)\right\rangle+(1 / 4) \int \mathrm{d}^{2} \alpha \mathrm{P}(\alpha)\left[\exp (-2 \mathrm{i} \omega \mathrm{t}) \alpha^{* 2}+\exp (2 \mathrm{i} \omega \mathrm{t}) \alpha^{2}-\left\langle\mathrm{A}^{2}+\mathrm{A}^{\dagger 2}\right\rangle\right]^{2}
$$

where $\mathrm{P}(\alpha)$ is the coherent-state quasi-probability function. A classical state, satisfy the relation from equation (7) as

$$
\left(\Delta \mathrm{Y}_{\mathrm{i}}\right)^{2} \geq\left\langle\left(\mathrm{N}_{\mathrm{A}}+1 / 2\right)\right\rangle
$$

A coherent state is that for which the variances of field quadratures satisfy the equation

$$
\left(\Delta \mathrm{Y}_{\mathrm{i}}\right)^{2}=\left\langle\left(\mathrm{N}_{\mathrm{A}}+1 / 2\right)\right\rangle
$$

\subsection{Difference squeezing of two modes}

The degenerate six-wave (DSW) energy level model [37, 38] is shown in Figure1, in which the process involving absorption of two pump photons of frequency $\omega_{1}$ each and emission of three Stokes photons of frequency $\omega_{2}$ and one signal photon at frequency $\omega_{3}$ to the initial state.

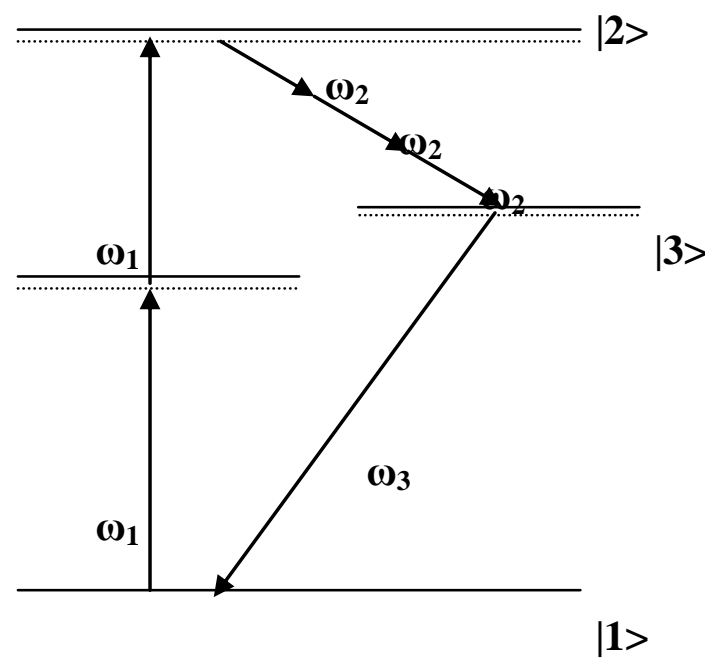

Figure 1: Six-wave energy level diagram 
Let us define difference of the fields of frequency $\omega_{1}$ and $\omega_{2}$ with creation (annihilation) operators $\mathrm{a}^{\dagger}(\mathrm{a})$ and $\mathrm{b}^{\dagger}(\mathrm{b})$ respectively, through variables $\mathrm{W}_{1}$ and $\mathrm{W}_{2}$ as

$$
\begin{array}{r}
\mathrm{W}_{1}=(1 / 2)\left(\mathrm{A}^{2} \mathrm{~B}^{\dagger 3}+\mathrm{A}^{\dagger 2} \mathrm{~B}^{3}\right) \\
\text { and } \mathrm{W}_{2}=(1 / 2 \mathrm{i})\left(\mathrm{A}^{2} \mathrm{~B}^{\dagger 3}-\mathrm{A}^{\dagger 2} \mathrm{~B}^{3}\right)
\end{array}
$$

The operators $\mathrm{W}_{1}$ and $\mathrm{W}_{2}$ satisfy the commutation relation as

$$
\left[\mathrm{W}_{1}, \mathrm{~W}_{2}\right]=\frac{1}{2 i}\left[9 \mathrm{~N}_{\mathrm{A}}^{2} \mathrm{~N}_{\mathrm{B}}^{2}+18 \mathrm{~N}_{\mathrm{A}}^{2} \mathrm{~N}_{\mathrm{B}}-2 \mathrm{~N}_{\mathrm{B}}^{3}+6 \mathrm{~N}_{\mathrm{A}}^{2}-4 \mathrm{~N}_{\mathrm{A}} \mathrm{N}_{\mathrm{B}}^{3}\right]
$$

and the uncertainty relation $(\hbar=1)$

$$
\Delta \mathrm{W}_{1} \Delta \mathrm{W}_{2} \geq \frac{1}{4}\left\langle 9 \mathrm{~N}_{\mathrm{A}}^{2} \mathrm{~N}_{\mathrm{B}}^{2}+18 \mathrm{~N}_{\mathrm{A}}^{2} \mathrm{~N}_{\mathrm{B}}-2 \mathrm{~N}_{\mathrm{B}}^{3}+6 \mathrm{~N}_{\mathrm{A}}^{2}-4 \mathrm{~N}_{\mathrm{A}} \mathrm{N}_{\mathrm{B}}^{3}\right\rangle
$$

where $\mathrm{N}_{\mathrm{A}}=\mathrm{A}^{\dagger} \mathrm{A}$ and $\mathrm{N}_{\mathrm{B}}=\mathrm{B}^{\dagger} \mathrm{B}$ are the photon number operator.

A state is said to be difference squeezing in $\mathrm{W}_{\mathrm{j}}$ direction if the condition follows

$$
\left(\Delta \mathrm{W}_{\mathrm{j}}\right)^{2}<\frac{1}{4}\left\langle 9 \mathrm{~N}_{\mathrm{A}}^{2} \mathrm{~N}_{\mathrm{B}}^{2}+18 \mathrm{~N}_{\mathrm{A}}^{2} \mathrm{~N}_{\mathrm{B}}-2 \mathrm{~N}_{\mathrm{B}}^{3}+6 \mathrm{~N}_{\mathrm{A}}^{2}-4 \mathrm{~N}_{\mathrm{A}} \mathrm{N}_{\mathrm{B}}^{3}\right\rangle \text { where } \mathrm{j}=1 \text { or } 2
$$

In terms of the $\mathrm{P}$ representation $\mathrm{P}(\alpha, \beta)$ for two-mode state, we have

$$
\begin{aligned}
\left(\Delta \mathrm{W}_{\mathrm{j}}\right)^{2}= & \frac{1}{4}\left\langle 9 \mathrm{~N}_{\mathrm{A}}^{2} \mathrm{~N}_{\mathrm{B}}^{2}+18 \mathrm{~N}_{\mathrm{A}}^{2} \mathrm{~N}_{\mathrm{B}}-2 \mathrm{~N}_{\mathrm{B}}^{3}+6 \mathrm{~N}_{\mathrm{A}}^{2}-4 \mathrm{~N}_{\mathrm{A}} \mathrm{N}_{\mathrm{B}}^{3}\right\rangle \\
& +(1 / 4) \int \mathrm{d}^{2} \alpha \int \mathrm{d}^{2} \beta \mathrm{P}(\alpha, \beta)\left[\left\{\exp \left(3 i \omega_{2} \mathrm{t}\right) \alpha^{2} \beta^{* 3} \pm \exp \left(-3 i \omega_{2} \mathrm{t}\right) \alpha^{*^{2}} \beta^{3}\right\}-\left\langle\mathrm{W}_{\mathrm{j}}\right\rangle\right]^{2}
\end{aligned}
$$

where \pm represents for $\mathrm{j}=1$ or 2 respectively.

\section{DIFFERENCE SQUEEZING OF THE OPTICAL FIELDS IN SIGNAL MODE IN DSW INTERACTION PROCESS}

From figure 1, the Hamiltonian can be written as

$$
\mathrm{H}=\omega_{1} \mathrm{a}^{\dagger} \mathrm{a}+\omega_{2} \mathrm{~b}^{\dagger} \mathrm{b}+\omega_{3} \mathrm{c}^{\dagger} \mathrm{c}+\mathrm{g}\left(\mathrm{a}^{2} \mathrm{~b}^{\dagger 3} \mathrm{c}^{\dagger}+\mathrm{a}^{\dagger 2} \mathrm{~b}^{3} \mathrm{c}\right)
$$

where $\mathrm{a}^{\dagger}(\mathrm{a}), \mathrm{b}^{\dagger}$ (b) and $\mathrm{c}^{\dagger}$ (c) are the creation (annihilation) operators of the pump field (A-mode), Stokes field (B-mode) and signal field (C-mode) respectively and $\mathrm{g}$ is the coupling constant per second. Since, A, B and C are slowly varying operators defined as, $A=a \exp \left(i \omega_{1} t\right), B=b \exp \left(i \omega_{2} t\right)$ and $C=c \exp \left(i \omega_{3} t\right)$ with the relation $2 \omega_{1}=3 \omega_{2}+\omega_{3}$.

Using interaction Hamiltonian of equation (16) in coupled Heisenberg equation of motion

$$
\dot{\mathrm{A}}=\frac{\partial \mathrm{A}}{\partial \mathrm{t}}+\mathrm{i}[\mathrm{H}, \mathrm{A}] \quad(\hbar=1)
$$

we obtain $\quad \dot{\mathrm{A}}=-2 \mathrm{igA} \mathrm{A}^{\dagger} \mathrm{C}$

Similarly $\quad \dot{B}=-3 \operatorname{igA}{ }^{2} B^{\dagger 2} C^{\dagger}$

and

$$
\dot{\mathrm{C}}=-\operatorname{igA}{ }^{2} \mathrm{~B}^{\dagger 3}
$$

Let us investigate the dependence of squeezing in the $\mathrm{C}$ - mode on the difference of the fundamental mode and stokes mode under short-time approximation (the short interaction time $\left(\approx 10^{-10} \mathrm{sec}\right)$ and $\left.\mathrm{gt}<<1\right)$.

Using equations (18) and (19) we obtain from equation (20)

$$
\ddot{\mathrm{C}}=-|\mathrm{g}|^{2}\left[9 \mathrm{~N}_{\mathrm{A}}^{2} \mathrm{~N}_{\mathrm{B}}^{2}+18 \mathrm{~N}_{\mathrm{A}}^{2} \mathrm{~N}_{\mathrm{B}}-2 \mathrm{~N}_{\mathrm{B}}^{3}+6 \mathrm{~N}_{\mathrm{A}}^{2}-4 \mathrm{~N}_{\mathrm{A}} \mathrm{N}_{\mathrm{B}}^{3}\right] \mathrm{C}
$$

In the interaction Hamiltonian the coupling constant is used $|\mathrm{g}|^{2}$ in place of $\mathrm{g}^{2}$.

Using short-time interaction time and keep terms up to second-order in 'gt' in the Taylor's expansion, we get 


$$
\mathrm{C}(\mathrm{t})=\mathrm{C}(0)+\mathrm{t} \dot{\mathrm{C}}(0)+\left(\mathrm{t}^{2} / 2 !\right) \ddot{\mathrm{C}}(0)+
$$

Use of equations (20) and (21) in equation (22), gives

$$
\mathrm{C}(\mathrm{t})=\mathrm{C}-\operatorname{igt} \mathrm{A}^{2} \mathrm{~B}^{\dagger 3}-\left(\frac{|g|^{2} t^{2}}{2}\right)\left(9 \mathrm{~N}_{\mathrm{A}}^{2} \mathrm{~N}_{\mathrm{B}}^{2}+18 \mathrm{~N}_{\mathrm{A}}^{2} \mathrm{~N}_{\mathrm{B}}-2 \mathrm{~N}_{\mathrm{B}}^{3}+6 \mathrm{~N}_{\mathrm{A}}^{2}-4 \mathrm{~N}_{\mathrm{A}} \mathrm{N}_{\mathrm{B}}^{3}\right) \mathrm{C}
$$

and $\mathrm{C}^{\dagger}(\mathrm{t})=\mathrm{C}^{\dagger}+\operatorname{igt} \mathrm{A}^{\dagger 2} \mathrm{~B}^{3}-\left(\frac{|g|^{2} t^{2}}{2}\right)\left(9 \mathrm{~N}_{\mathrm{A}}^{2} \mathrm{~N}_{\mathrm{B}}^{2}+18 \mathrm{~N}_{\mathrm{A}}^{2} \mathrm{~N}_{\mathrm{B}}-2 \mathrm{~N}_{\mathrm{B}}^{3}+6 \mathrm{~N}_{\mathrm{A}}^{2}-4 \mathrm{~N}_{\mathrm{A}} \mathrm{N}_{\mathrm{B}}^{3}\right) \mathrm{C}^{\dagger}$

where the operators at $\mathrm{t}=0$ represents $\mathrm{C}(0)=\mathrm{C}$ throughout the paper.

In order to examine the existence of squeezing in the signal mode, we define

$$
\begin{aligned}
& \mathrm{X}_{1 \mathrm{C}}(\mathrm{t}) & =(1 / 2)\left[\mathrm{C}(\mathrm{t})+\mathrm{C}^{\dagger}(\mathrm{t})\right] \\
\text { and } & \mathrm{X}_{2 \mathrm{C}}(\mathrm{t}) & =(1 / 2 \mathrm{i})\left[\mathrm{C}(\mathrm{t})-\mathrm{C}^{\dagger}(\mathrm{t})\right]
\end{aligned}
$$

Using equations (23) and (24) in equations (25) and (26) we obtain

$\mathrm{X}_{1 \mathrm{C}}(\mathrm{t})=\mathrm{X}_{1 \mathrm{C}}+\lg \mid \mathrm{t}\left(\mathrm{W}_{2}\right)-\left(\frac{|g|^{2} t^{2}}{2}\right)\left(9 \mathrm{~N}_{\mathrm{A}}^{2} \mathrm{~N}_{\mathrm{B}}^{2}+18 \mathrm{~N}_{\mathrm{A}}^{2} \mathrm{~N}_{\mathrm{B}}-2 \mathrm{~N}_{\mathrm{B}}^{3}+6 \mathrm{~N}_{\mathrm{A}}^{2}-4 \mathrm{~N}_{\mathrm{A}} \mathrm{N}_{\mathrm{B}}^{3}\right) \mathrm{X}_{1 \mathrm{C}}$

and

$\mathrm{X}_{2 \mathrm{C}}(\mathrm{t})=\mathrm{X}_{2 \mathrm{C}}-|\mathrm{g}| \mathrm{t}\left(\mathrm{W}_{1}\right)-\left(\frac{|g|^{2} t^{2}}{2}\right)\left(9 \mathrm{~N}_{\mathrm{A}}^{2} \mathrm{~N}_{\mathrm{B}}^{2}+18 \mathrm{~N}_{\mathrm{A}}^{2} \mathrm{~N}_{\mathrm{B}}-2 \mathrm{~N}_{\mathrm{B}}^{3}+6 \mathrm{~N}_{\mathrm{A}}^{2}-4 \mathrm{~N}_{\mathrm{A}} \mathrm{N}_{\mathrm{B}}^{3}\right) \mathrm{X}_{2 \mathrm{C}}$

At $\mathrm{t}=0$ the modes A and B are uncorrelated, then equations (27) and (28) may be written as,

$\left[\Delta \mathrm{X}_{1 \mathrm{C}}(\mathrm{t})\right]^{2}=\left(\Delta \mathrm{X}_{1 \mathrm{C}}\right)^{2}+|\mathrm{g}|^{2} \mathrm{t}^{2}\left(\Delta \mathrm{W}_{2}\right)^{2}$

$$
-|g|^{2} \mathrm{t}^{2}\left\langle 9 \mathrm{~N}_{\mathrm{A}}^{2} \mathrm{~N}_{\mathrm{B}}^{2}+18 \mathrm{~N}_{\mathrm{A}}^{2} \mathrm{~N}_{\mathrm{B}}-2 \mathrm{~N}_{\mathrm{B}}^{3}+6 \mathrm{~N}_{\mathrm{A}}^{2}-4 \mathrm{~N}_{\mathrm{A}} \mathrm{N}_{\mathrm{B}}^{3}\right\rangle\left(\Delta \mathrm{X}_{1 \mathrm{C}}\right)^{2}
$$

and $\quad\left[\Delta \mathrm{X}_{2 \mathrm{C}}(\mathrm{t})\right]^{2}=\left(\Delta \mathrm{X}_{2 \mathrm{C}}\right)^{2}+|\mathrm{g}|^{2} \mathrm{t}^{2}\left(\Delta \mathrm{W}_{1}\right)^{2}$

$$
-|g|^{2} t^{2}\left\langle 9 N_{A}^{2} N_{B}^{2}+18 N_{A}^{2} N_{B}-2 N_{B}^{3}+6 N_{A}^{2}-4 N_{A} N_{B}^{3}\right\rangle\left(\Delta X_{2 C}\right)^{2}
$$

If the $\mathrm{C}$ mode is initially in a coherent state, then

$$
\left(\Delta \mathrm{X}_{1 \mathrm{C}}\right)^{2}=\left(\Delta \mathrm{X}_{2 \mathrm{C}}\right)^{2}=1 / 4
$$

Equations (29) and (30) reduce to

$$
\begin{aligned}
{\left[\Delta \mathrm{X}_{1 \mathrm{C}}(\mathrm{t})\right]^{2} } & =\left(\frac{1}{4}\right)+|\mathrm{g}|^{2} \mathrm{t}^{2}\left[\left(\Delta \mathrm{W}_{2}\right)^{2}-\left(\frac{1}{4}\right)\left\langle 9 \mathrm{~N}_{\mathrm{A}}^{2} \mathrm{~N}_{\mathrm{B}}^{2}+18 \mathrm{~N}_{\mathrm{A}}^{2} \mathrm{~N}_{\mathrm{B}}-2 \mathrm{~N}_{\mathrm{B}}^{3}+6 \mathrm{~N}_{\mathrm{A}}^{2}-4 \mathrm{~N}_{\mathrm{A}} \mathrm{N}_{\mathrm{B}}^{3}\right\rangle\right] \\
\text { and }\left[\Delta \mathrm{X}_{2 \mathrm{C}}(\mathrm{t})\right]^{2} & =\left(\frac{1}{4}\right)+|\mathrm{g}|^{2} \mathrm{t}^{2}\left[\left(\Delta \mathrm{W}_{1}\right)^{2}-\left(\frac{1}{4}\right)\left\langle 9 \mathrm{~N}_{\mathrm{A}}^{2} \mathrm{~N}_{\mathrm{B}}^{2}+18 \mathrm{~N}_{\mathrm{A}}^{2} \mathrm{~N}_{\mathrm{B}}-2 \mathrm{~N}_{\mathrm{B}}^{3}+6 \mathrm{~N}_{\mathrm{A}}^{2}-4 \mathrm{~N}_{\mathrm{A}} \mathrm{N}_{\mathrm{B}}^{3}\right\rangle\right]
\end{aligned}
$$

We rewrite equations (32) and (33) as follows

$$
\left[\Delta \mathrm{X}_{1 \mathrm{C}}(\mathrm{t})\right]^{2}-\left(\frac{1}{4}\right)=|\mathrm{g}|^{2} \mathrm{t}^{2}\left[\left(\Delta \mathrm{W}_{2}\right)^{2}-\left(\frac{1}{4}\right)\left\langle 9 \mathrm{~N}_{\mathrm{A}}^{2} \mathrm{~N}_{\mathrm{B}}^{2}+18 \mathrm{~N}_{\mathrm{A}}^{2} \mathrm{~N}_{\mathrm{B}}-2 \mathrm{~N}_{\mathrm{B}}^{3}+6 \mathrm{~N}_{\mathrm{A}}^{2}-4 \mathrm{~N}_{\mathrm{A}} \mathrm{N}_{\mathrm{B}}^{3}\right\rangle\right]
$$


and $\left[\Delta \mathrm{X}_{2 \mathrm{C}}(\mathrm{t})\right]^{2}-\left(\frac{1}{4}\right)=|\mathrm{g}|^{2} \mathrm{t}^{2}\left[\left(\Delta \mathrm{W}_{1}\right)^{2}-\left(\frac{1}{4}\right)\left\langle 9 \mathrm{~N}_{\mathrm{A}}^{2} \mathrm{~N}_{\mathrm{B}}^{2}+18 \mathrm{~N}_{\mathrm{A}}^{2} \mathrm{~N}_{\mathrm{B}}-2 \mathrm{~N}_{\mathrm{B}}^{3}+6 \mathrm{~N}_{\mathrm{A}}^{2}-4 \mathrm{~N}_{\mathrm{A}} \mathrm{N}_{\mathrm{B}}^{3}\right\rangle\right]$

These equations (34) and (35) establish the relation between difference squeezing of the fields fundamental and Stokes modes and normal squeezing of the field signal mode in degenerate six-wave interaction process. We observe that if the input state is difference squeezed in the $\mathrm{W}_{2}$ or $\mathrm{W}_{1}$ direction, then difference-frequency generation will produce an output, and will lead to normal squeezing in $\mathrm{X}_{1 \mathrm{C}}$ or $\mathrm{X}_{2 \mathrm{C}}$ respectively. It is found that difference squeezing can be turned into normal squeezing. This finding suggests a method of detection for difference squeezing by DSW interaction process.

In order to study the squeezing in signal mode, let us assume Stokes mode as a constant and represent a constant term $\mathrm{m}$ for $\mathrm{B}$ and $\mathrm{B}^{\dagger}$ so that the change in the $\mathrm{B}$ mode is negligible.

Hence equation (20) becomes

$$
\dot{\mathrm{C}}=-i g \mathrm{~A}^{2} \mathrm{~m}^{3}
$$

and $\ddot{\mathrm{C}}=-2|\mathrm{~g}|^{2} \mathrm{~m}^{6}\left(2 \mathrm{~N}_{\mathrm{A}}+1\right) \mathrm{C}$

Using equation (22), we have

$$
\mathrm{C}(\mathrm{t})=\mathrm{C}-\mathrm{i}|\mathrm{g}| \mathrm{m}^{3} \mathrm{t} \mathrm{A}^{2}-|\mathrm{g}|^{2} \mathrm{t}^{2} \mathrm{~m}^{6}\left(2 \mathrm{~N}_{\mathrm{A}}+1\right) \mathrm{C}
$$

and $\quad C^{\dagger}(t)=C^{\dagger}+i|g| m^{3} t A^{\dagger 2}-|g|^{2} t^{2} m^{6}\left(2 N_{A}+1\right) C^{\dagger}$

Using equations (38) and (39) in equations (25) and (26), we get

$$
X_{1 C}(t)=X_{1 C}+|g| m^{3} t Y_{2 A}-|g|^{2} t^{2} m^{6}\left(2 N_{A}+1\right) X_{1 C}
$$

and $\quad X_{2 C}(t)=X_{2 C}-|g| m^{3} t Y_{1 A}-|g|^{2} t^{2} m^{6}\left(2 N_{A}+1\right) X_{2 C}$

where $Y_{1 A}$ and $Y_{2 A}$ define in equations (1) and (2).

At $\mathrm{t}=0$, the modes are uncorrelated, then equations (40) and (41) becomes

$$
\left[\Delta \mathrm{X}_{1 \mathrm{C}}(\mathrm{t})\right]^{2}=\left(\Delta \mathrm{X}_{1 \mathrm{C}}\right)^{2}+|\mathrm{g}|^{2} \mathrm{~m}^{6} \mathrm{t}^{2}\left[\left(\Delta \mathrm{Y}_{2 \mathrm{~A}}\right)^{2}-2\left\langle 2 \mathrm{~N}_{\mathrm{A}}+1\right\rangle\left(\Delta \mathrm{X}_{1 \mathrm{C}}\right)^{2}\right]
$$

and $\quad\left[\Delta \mathrm{X}_{2 \mathrm{C}}(\mathrm{t})\right]^{2}=\left(\Delta \mathrm{X}_{2 \mathrm{C}}\right)^{2}+|\mathrm{g}|^{2} \mathrm{~m}^{6} \mathrm{t}^{2}\left[\left(\Delta \mathrm{Y}_{1 \mathrm{~A}}\right)^{2}-2\left\langle 2 \mathrm{~N}_{\mathrm{A}}+1\right\rangle\left(\Delta \mathrm{X}_{2 \mathrm{C}}\right)^{2}\right]$

Using equation (31), then we obtains

$$
\begin{array}{ll} 
& {\left[\Delta \mathrm{X}_{1 \mathrm{C}}(\mathrm{t})\right]^{2}-1 / 4=|\mathrm{g}|^{2} \mathrm{~m}^{6} \mathrm{t}^{2}\left[\left(\Delta \mathrm{Y}_{2 \mathrm{~A}}\right)^{2}-\left\langle\mathrm{N}_{\mathrm{A}}+1 / 2\right\rangle\right]} \\
\text { and } & {\left[\Delta \mathrm{X}_{2 \mathrm{C}}(\mathrm{t})\right]^{2}-1 / 4=|\mathrm{g}|^{2} \mathrm{~m}^{6} \mathrm{t}^{2}\left[\left(\Delta \mathrm{Y}_{1 \mathrm{~A}}\right)^{2}-\left\langle\mathrm{N}_{\mathrm{A}}+1 / 2\right\rangle\right]}
\end{array}
$$

Equations (44) and (45) show that $X_{1 C}$ is squeezed if $Y_{2 A}$ is squeezed and $X_{2 C}$ is squeezed if $Y_{1 A}$ is squeezed. That means the $C$ mode is squeezed in the $\mathrm{X}_{1 \mathrm{C}}$ direction if the A mode is amplitude-squared squeezed in the $\mathrm{Y}_{2 \mathrm{~A}}$ direction and the $\mathrm{C}$ mode is squeezed in the $\mathrm{X}_{2 \mathrm{C}}$ direction if the $\mathrm{A}$ mode is amplitude-squared squeezing in the $\mathrm{Y}_{1 \mathrm{~A}}$ direction. That is, if a fundamental mode with amplitude-squared squeezing propagates through a nonlinear medium then normal squeezing will generate in the signal mode. It is shown that amplitude-squared squeezing can be turned into normal squeezing. This result suggests a method of detection for amplitude-squared squeezing by DSW interaction process.

In earlier publication [35], the results of second-order squeezing in spontaneous and stimulated interaction process are quoted below as

$$
\left[\Delta \mathrm{Y}_{1 \mathrm{~A}}(\mathrm{t})\right]^{2}-\left\langle\mathrm{N}_{1 \mathrm{~A}}(\mathrm{t})+1 / 2\right\rangle=-12|\mathrm{~g}|^{2} \mathrm{t}^{2}\left[|\alpha|^{4}(\cos 4 \theta+2)+4|\alpha|^{2}+1 / 2\right]
$$

and $\quad\left[\Delta \mathrm{Y}_{1 \mathrm{~A}}(\mathrm{t})\right]^{2}-\left\langle\mathrm{N}_{1 \mathrm{~A}}(\mathrm{t})+1 / 2\right\rangle=-12|\mathrm{~g}|^{2} \mathrm{t}^{2}\left(|\beta|^{2}+1\right)\left[|\alpha|^{4}(\cos 4 \theta+2)+4|\alpha|^{2}+1 / 2\right]$

where $|\alpha|^{2}=\left\langle\mathrm{A}^{\dagger} \mathrm{A}\right\rangle,|\beta|^{2}=\left\langle\mathrm{B}^{\dagger} \mathrm{B}\right\rangle$ and $\theta$ is the phase angle.

Let us take only the $\mathrm{Y}_{1 \mathrm{~A}}(\mathrm{t})$ quadrature and using equations (46) and (47) in equation (45), we obtain

$$
\left[\Delta \mathrm{X}_{2 \mathrm{C}}(\mathrm{t})\right]^{2}-1 / 4=-12|\mathrm{~g}|^{4} \mathrm{t}^{4} \mathrm{~m}^{6}\left[|\alpha|^{4}(\cos 4 \theta+2)+4|\alpha|^{2}+1 / 2\right]
$$

and

$$
\left[\Delta \mathrm{X}_{2 \mathrm{C}}(\mathrm{t})\right]^{2}-1 / 4=-12|\mathrm{~g}|^{4} \mathrm{t}^{4} \mathrm{~m}^{6}\left(|\beta|^{2}+1\right)\left[|\alpha|^{4}(\cos 4 \theta+2)+4|\alpha|^{2}+1 / 2\right]
$$

The additional factor $\left(|\beta|^{2}+1\right)$ in equation (49) is due to stimulated interaction. This establishes occurrence of normal squeezing in the signal mode. Similar calculation can be done for $\mathrm{Y}_{2 \mathrm{~A}}$ quadrature. 
An analysis of equations (46 - 49) shows that

if $\mathrm{g}^{2} \mathrm{t}^{2} \mathrm{~m}^{6}>1$, squeezing is greater in signal mode compared to fundamental mode.

and, if $\mathrm{g}^{2} \mathrm{t}^{2} \mathrm{~m}^{6}<1$, corresponding squeezing is larger in fundamental mode.

\section{RESULTS AND DISCUSSION}

We plot a graph (figure 2) between left hand side of equation (34) say $\mathrm{D}_{\mathrm{S}}$ and $|\mathrm{gt}|$ with typical values $\left(\Delta \mathrm{W}_{2}\right)^{2}=\left(\Delta \mathrm{W}_{2}\right)^{2}$ $=\left(\frac{1}{4}\right)$ and $\left\langle\mathrm{N}_{\mathrm{A}}\right\rangle=1,2,3 \ldots$ but $\left\langle\mathrm{N}_{\mathrm{A}}\right\rangle \neq 0$ and $\left\langle\mathrm{N}_{\mathrm{B}}\right\rangle=0,1 \ldots$ so that it could satisfy the equation (14).

The curves infer that the difference squeezing exists and responses nonlinearly to the number of pump photons. It also shows that the squeezing in the pump mode is depends on coupling of the field amplitude and interaction time.

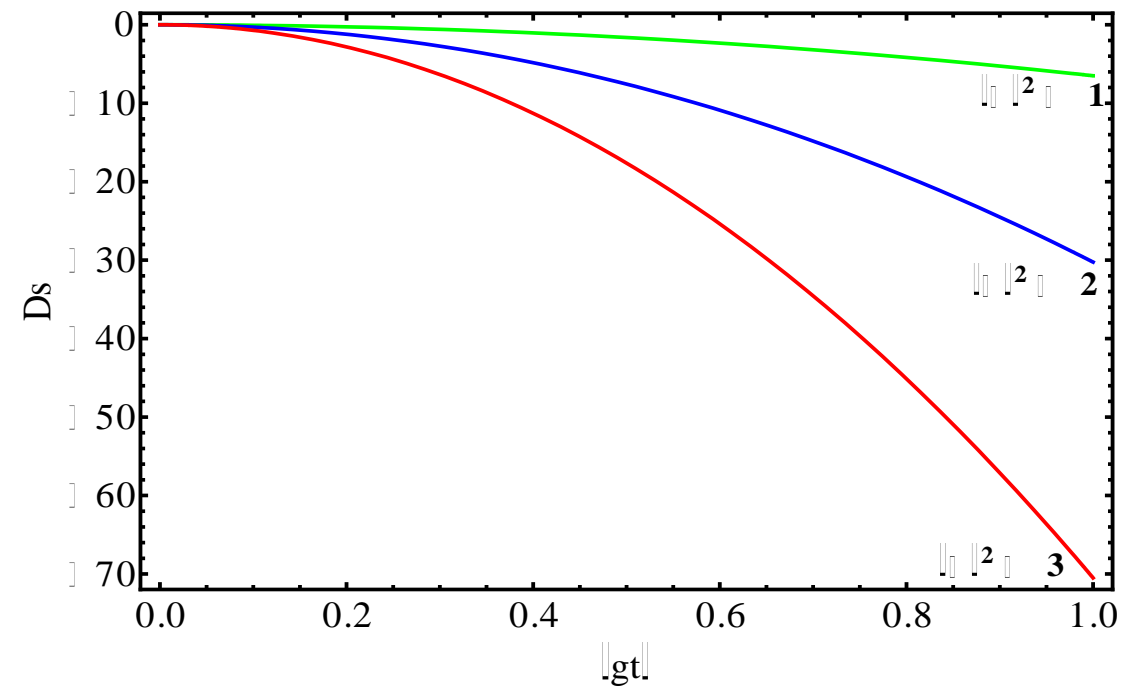

Figure 2: Variation of difference squeezing $\mathrm{D}_{\mathrm{S}}$ with $|\mathrm{gt}|$ in DSW interaction process

(when $|\alpha|^{2}=1,2,3$ and $|\beta|^{2}=1$ )

Let us denote left hand side of equation (48) by $\mathrm{S}$ and plot a graph with $|\alpha|^{2}$ having different values of $|\mathrm{gt}|^{2}$.

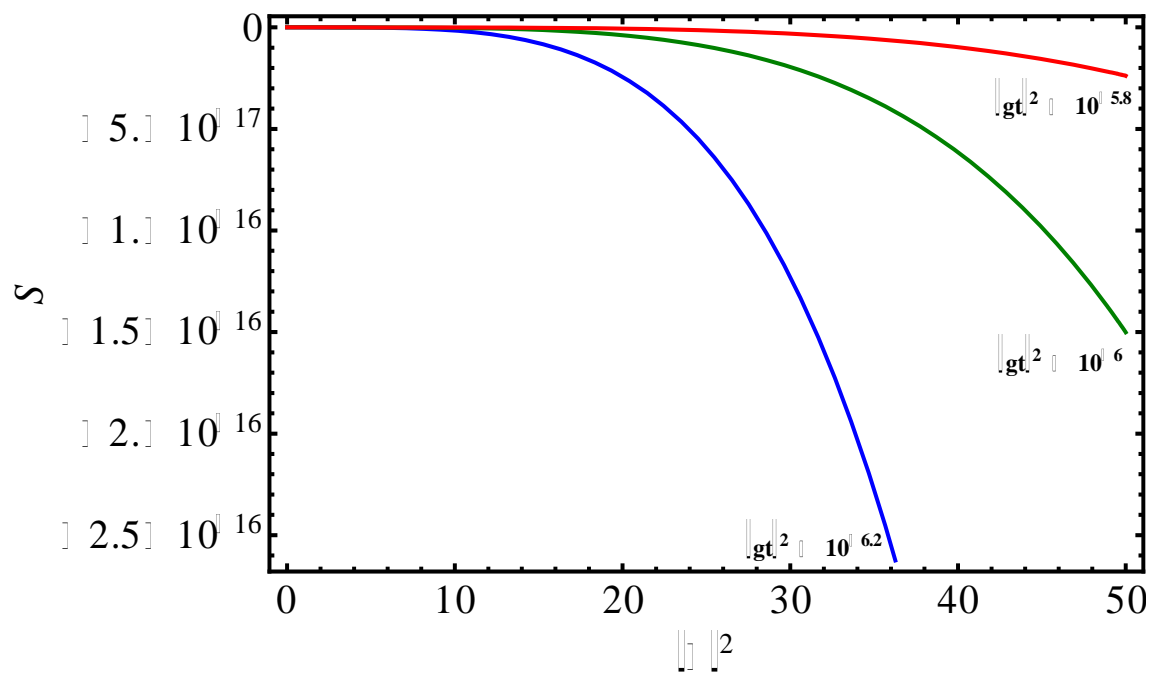

Figure 3: Variation of the squeezing S with $|\alpha|^{2}\left(\theta=0,|\beta|^{2}=0 \& \mathrm{~m}^{2}=1\right)$ in DSW interaction process 
Figure 3 shows that the squeezing in signal mode is greater than the corresponding squeezing in pump mode [35]. It confirms that the higher order squeezing is directly associated with the coupling of the field and interaction time. Hence more squeezing can be observed in short time scale.

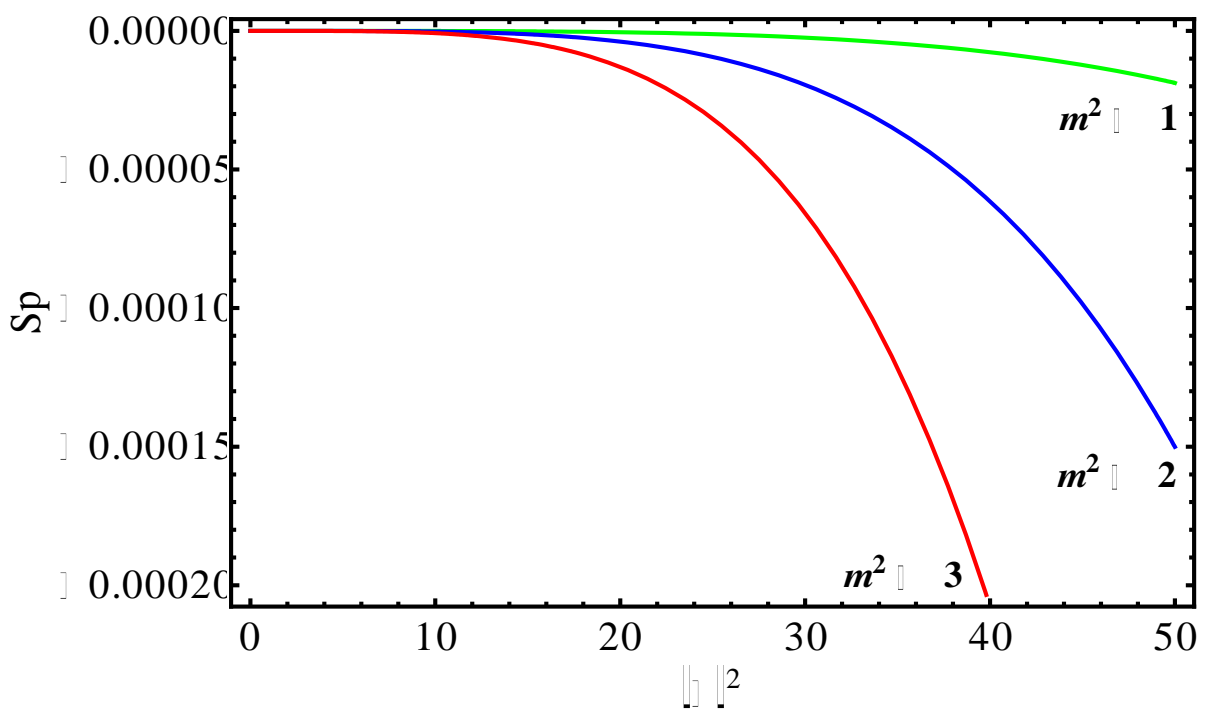

Figure 4: Variation of the squeezing $S_{\mathrm{P}}$ in signal mode with $|\alpha|^{2}\left(|\beta|^{2}=0\right)$ in spontaneous DSW interaction process

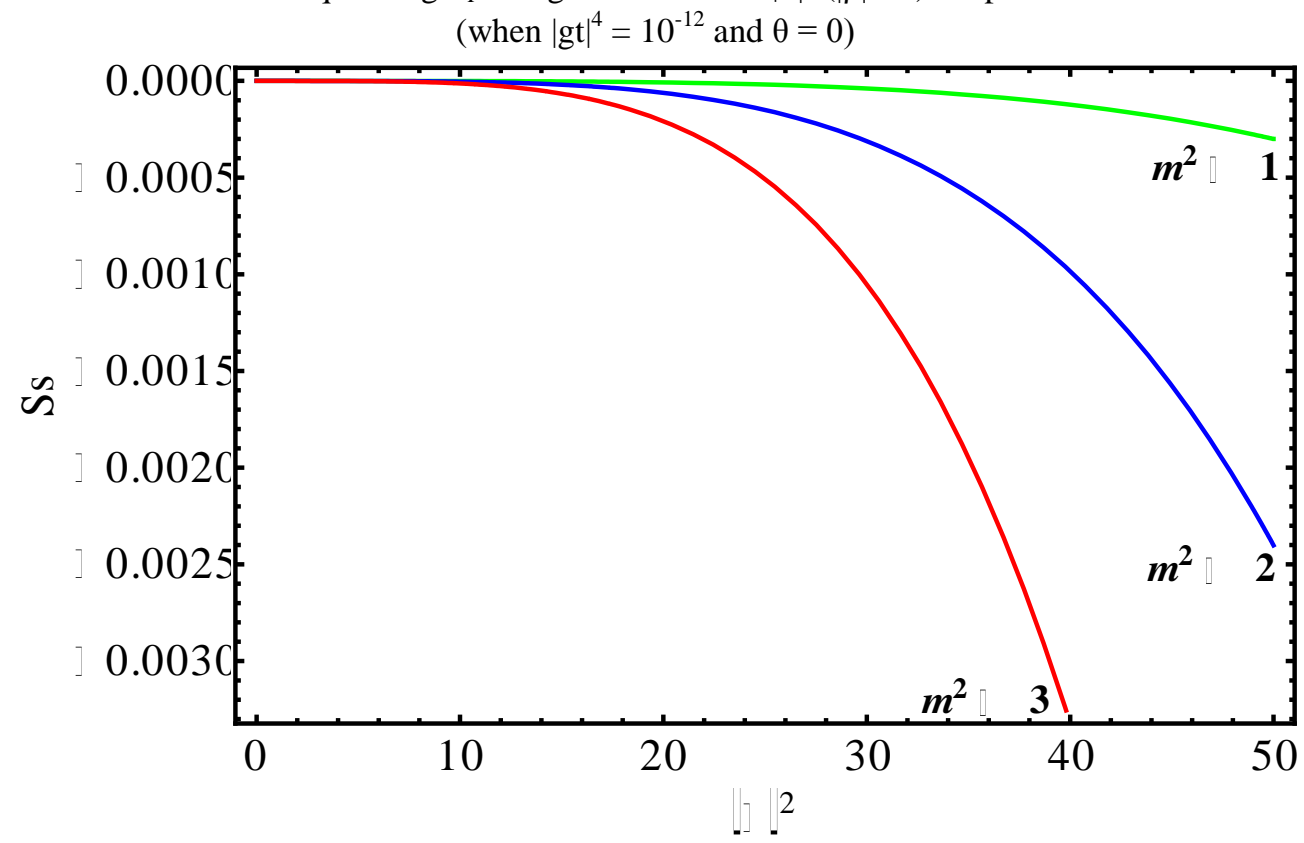

Figure 5: Variation of the squeezing $S_{S}$ in signal mode with $|\alpha|^{2}\left(|\beta|^{2}=4\right)$ in stimulated DSW interaction process (when

$$
|\mathrm{gt}|^{4}=10^{-12} \text { and } \theta=0 \text { ) }
$$

To study higher-order squeezing, we denote the right hand side of equations (48) and (49) respectively by $S_{p}$ and $S_{s}$. Taking $|\mathrm{gt}|^{2}=10^{-6}$ and $\theta=0$ (for maximum squeezing), the variations of $S_{\mathrm{p}}$ and $\mathrm{S}_{\mathrm{s}}$ are shown in Figures 4 and 5 for constant $\mathrm{m}^{2}=1,2$ and 3 (arbitrary values). 
Figures 4 and 5 show that the squeezing increases nonlinearly with $|\alpha|^{2}$ i.e. the number of pump photons. Further, in stimulated process squeezing also increases with $|\beta|^{2}$ that is the photon number in B mode. This confirms that the squeezed states are associated with large number of photons. It shows that squeezing is more in stimulated process than spontaneous one.

\section{CONCLUSIONS AND FUTURE SCOPE}

In this paper we observed that if the input state is difference squeezed in the $\mathrm{W}_{2}$ or $\mathrm{W}_{1}$ direction, and then difference-frequency generation will produce an output, and will lead to normal squeezing in $\mathrm{X}_{1 \mathrm{C}}$ or $\mathrm{X}_{2 \mathrm{C}}$ respectively. It is shown that difference squeezing of the optical fields can be turned into normal squeezing by degenerate six-wave interaction process. The present result suggests a method of detection for difference squeezing in degenerate six-wave interaction process. The difference squeezing responses nonlinearly to the number of pump photons. Hence higher-order squeezing is found to be dependent on coupling of the field amplitude and interaction time. This confirms the Hillery's result [23].

When an amplitude-squared squeezing of the fundamental mode propagates through a nonlinear medium then normal squeezing will generate in the signal mode. The nonlinear interaction (signal mode) converts higher-order squeezing into normal squeezing. It suggests a method of detection for amplitude-squared squeezing in degenerate six wave interaction process.

The squeezing obtained in the present paper in degenerate six-wave signal mode is found to be greater than the corresponding squeezing in fundamental mode [35]. It is found that squeezing is greater in stimulated process than in spontaneous interaction. It is concluded that squeezing can be enhanced in signal mode providing stokes mode assume as constant term.

The above findings stated that the process with higher-order non-linearity is more suitable for generation of optimum squeezed light. These results suggest ways for obtaining greater noise reduction in optical systems and can be useful in high quality telecommunication.

\section{ACKNOWLEDGMENTS}

We would like to thank the referees for his comments and valuable suggestions.

\section{REFERENCES}

[1] D. F. Walls, "Squeezed states of light” Nature 306 141-146 (1983).

[2] J. Perina, "Quantum Statistics of Linear and Nonlinear Optical Phenomena” Kluwer, Dordrecht, Chapters 9 and 10 (1991).

[3] B. E. A. Saleh and M. C. Teich, "Can the channel capacity of a light-wave communication system be increased by the use of photon-numbersqueezed light?” Phys. Rev. Lett. 58 2656-2659 (1987).

[4] Special issue on squeezed states, J. Mod. Opt. 34 (1987).

[5] H.P. Yuen, J.H. Shapiro, "Optical communication with two-photon coherent states-part I: quantum-state propagation and quantum-noise reduction” IEEE Trans. Inf. Theory. 24, 657-668 (1978).

[6] C.H.Bennett, G.Brassard and N.D. Mermin, “Quantum cryptography without Bell's theorem” Phys Rev.Lett. 68, 557-559 (1992).

[7] J. Kempe, "Multipartite entanglement and its applications to cryptography" Phys. Rev. A. 60, 910-916 (1999).

[8] C. K. Hong and L. Mandel "Generation of higher-order squeezing of quantum electromagnetic fields" Phys. Rev. A 32 974-982 (1985).

[9] D. K. Giri and P. S. Gupta, "Higher-order squeezing of the electromagnetic field in spontaneous and stimulated Raman process" J. Mod. Opt. 52 1769-1781 (2005).

[10] Ling-An Wu, H J Kimble, J L Hall, Huifa Wu, “Generation of Squeezed States by Parametric Down Conversion "Phys. Rev. Lett. 57 2520-2523 (1986).

[11] M Fernee, P Kinsler, P D Drummond, “Quadrature squeezing in the nondegenerate parametric amplifier” Phys. Rev. A51 864-867 (1995).

[12] L.Mandel, "Squeezing and photon antibunching in harmonic generation” Opt. Commun. 42, 437-439 (1982).

[13] J. Perina, V. Perinova and J. Kodousek, “On the relations of antibunching, sub-poissonian statistics and squeezing” Opt. Commun. $49210-214$ (1984).

[14] S. Kielich, R. Tanas and R. Zawodny, "Squeezing in the third-harmonic field generated by self-squeezed light" J. Opt. Soc. Am B 4 1627-1632 (1987). 
[15] M D Reid, D F Walls, “Quantum statistics of degenerate fourwave mixing”. Opt.Commun. 50, 406-410 (1984); "Generation of squeezed states via degenerate four-wave mixing”. Phys. Rev.A. 31, 1622 (1985).

[16] J. Perina, V. Perinova, C. Sibilia and M. Bertolotti, “Quantum statistics of four-wave mixing” Opt. Commun. 49 285-289 (1984).

[17] M. S. K. Razmi and J. H. Eberly, "Degenerate four-wave mixing and squeezing in pumped three-level atomic systems" Opt. Commun. 76 265-267 (1990).

[18] J Perina and J Krepelka, “Stimulated Raman scattering of squeezed light with pump depletion” J. Mod. Opt. 38 2137-2151 (1991).

[19] A. Kumar and P. S. Gupta, "Short-time squeezing in spontaneous Raman and stimulated Raman scattering” Quant. Semiclass. Opt. 7 835-841 (1995).

[20] A. Kumar and P. S. Gupta, "Higher-order amplitude squeezing in hyper-Raman scattering under short-time approximation" Quant. Semiclass. Opt. 8 1053-1060 (1996).

[21] C. K. Hong and L. Mandel, "Higher-order squeezing of a quantum field" Phys. Rev. Lett. 54 323-325 (1985).

[22] C. K. Hong and L. Mandel "Generation of higher-order squeezing of quantum electromagnetic fields" Phys. Rev. A 32 974-982 (1985).

[23] M. Hillery, "Squeezing of the square of the field amplitude in second harmonic generation" Opt. Commun. 62 135-138 (1987); "Amplitudesquared squeezing of the electromagnetic field" Phys. Rev. A 36 3796-3802 (1987).

[24] M. Hillery “Phase-space representation of amplitude-squared squeezing” Phys. Rev. A 45 4944-4950 (1992).

[25] You-bang Zhan, “Amplitude-cubed squeezing in harmonic generations" Phys. Lett. A 160 498-502 (1991).

[26] Y. Kim, T. H. Yoon, "Higher order sub-Poissonian photon statistics of light” Opt.Commun. 212, 107-114 (2002).

[27] H. Prakash, D. K. Mishra, "Higher order sub-Poissonian photon statistics and their use in detection of Hong and Mandel squeezing and amplitude-squared squeezing” J. Phys. B At.Mol.Opt. Phys. 39, 2291-2297 (2006).

[28] D. K. Mishra “Study of higher order non-classical properties of squeezed kerr state”. Opt. Commun. 283, 3284-3290 (2010).

[29] P Garcia-Fernandez, L Sainz De Los Terreros, F J Bermejo, J Santoro, "Higher-order squeezed states in a multiphoton absorption process" Phys. Lett. A118 400-404 (1986).

[30] M. Hillery, "Sum and difference squeezing of the electromagnetic field" Phys. Rev. A 40 3147-3155 (1989).

[31] Ashok Kumar and P. S. Gupta, "Difference squeezing in four-wave difference frequency generation" Quant. Semiclass. Opt. 10 485-492 (1998).

[32] D K Giri and P S Gupta, "Squeezing effects in the sum and difference of the field amplitude in the Raman process” Mod. Phys Lett. B 19 12611276 (2005).

[33] M. K. Olsen and R. J. Horowicz, "Squeezing in the sum and difference fields in second harmonic generation" Opt. Commun. 168 135-143 (1999).

[34] Nguyen Ba An and Vo Tinh, “General multimode difference-squeezing” Phys Lett. A 270 27-40 (2000).

[35] D. K. Giri and P. S. Gupta, "Short-time squeezing effects in spontaneous and stimulated six-wave mixing process" Opt. Commun. 221 135-143 (2003).

[36] D K Giri and P S Gupta, "The amplitude squeezing effects of the electromagnetic field in six-wave interaction model" Mod. Phys. Lett. B 22 219-230 (2008).

[37] M. Ducloy, “Optical phase conjugation with frequency up-conversion via high-order, nondegenerate multiwave mixing” Appl. Phys. Lett. 46 1020-1022 (1985).

[38] F. Charra and J. M. Nunzi, “Nondegenerate multiwave mixing in polydiacetylene: phase conjugation with frequency conversion" J. Opt. Soc. Am. B 8 570-577 (1991).

\section{AUTHORS PROFILE}

D K Giri pursed M.Phil. and Ph.D. in Applied Physics from IIT (ISM) Dhanbad in 2002 \& 2007. He is currently working as Assistant Professor in Department of Physics at P. K. Roy Memorial College, Dhanbad since 2008. He is a life member of various academic societies like LASSI, ISCA, IAPT, ILA. He has published more than 21 research papers in reputed international journals including Thomson Reuters (SCI \& Web of Science). His main research work focuses on Nonlinear Optics, Quantum Optics and Quantum Teleportation. He has 10 years of teaching experience and 13 years of research experience.

B K Choudhary qualified CSIR-UGC NET and pursuing Ph.D from Vinoba Bhave University, Hazaribagh Under Supervision of D K Giri .He is currently working as Assistant Professor in Department of Applied Physics at Cambridge institute of Technology(R), Tatisilwai, Ranchi. He has published 5 research paper in reputed international journal and 7 in national journal .He has presented 18 research paper in Intenational/national conference /seminar. His main research work focuses on Nonlinear Optics, Quantum Optics. He has 9 years of teaching experience and 6 years of research experience.

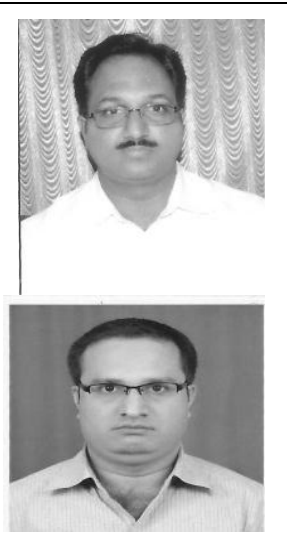

